THE election of Max von Laue to foreign membership of the Royal Society will give the greatest pleasure to his many friends in Great Britain and abroad. It is a feting recggnition of his life-time of scientific work and in a ticular of his discovery of the diffr ctide of A l l y a crystal lattice. In the year $19 \mathrm{~g}$ Laue $\mathrm{n}$ dole the suggestion that if X-rays wefe in eality electromagnetic waves like light, the regyialy spaced arrangement of atoms in a crystal might be expected to provide a grating of suitable scale to yield diffraction effects. The crucial experiment was carried out by two young research workers in the Physics Laboratory at the University of Munich, and its result was the first 'Laue photograph'. Two new branches of science have been founded on this original experiment. X-ray spectroscopy has played an important part in all investigations into the structure of the atom. Crystal analysis has led to an immense advance in our knowledge of the structure of matter of all kinds, and has profoundly modified many of our views in physics, chemistry, metallurgy and mineralogy. It may soon be possible to add biochemistry to this list. This deserved recognition of Laue's great scientific work will be universally welcomed; but to his personal friends it will afford an even deeper pleasure because of their affection for a brave, courteous and kindly man. The reception accorded to Laue when he was a guest at the meeting of the X-ray Analysis Group of the Institute of Physics soon after the end of the War was an index of the regard in which he is held by all who know him. It is hard to think of an election which could give more general satisfaction.

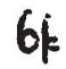

Prof. E. Schrödinger

ERWrN SCHRÖDINGER, born at Vienna in 1887 , comes from th distinguished Austrian school of physics of Hich Stefan, Loschmidt, Mach and Boltzmann were the most notable representatives. He begin his academic career in 1914 as PrivatDozent at the University of Vienna. Since 1920 he h f coupied chairs of theoretical physics in Stuttgart, BAfslat, Zurich and Berlin, where he was the successor of Max Planck. After Hitler's access to power in 1933, he left Germany of his own free will and went to Oxford. After a short interlude in Graz, which ended with the "Anschluss", he went to Dublin to become a member, and for a time director, of the newly founded Institute for Advanced Studies. Schrödinger's first publications cover a wide field, for example, vibrations and specific heat of crystals, quantum mechanics of spectra, and so on. Most remarkable are his investigations in the mathematical structure of the physiological colour-space. His international fame, however, is based on his wave mechanics of 1926. The series of papers, in which he developed an ingenious idea of de Broglie's to a complete theory of atomic structures, and demonstrated, moreover, the relation of his wave equation to other forms of quantum mechanics (Heisenberg Born - Jordan, Dirac), belong to the classics of theoretical physics by virtue of their depth, wealth, completeness and brilliant style. In recent years, Schrödinger has made great efforts to unify the different field theories of physics into a coherent system. He has further published several little books, one of which was a condensed presentation of statistical thermodynamics ; another, with the daring title "What is Life ?", being an expansion of the modern theory of heredity from the point of view of the physicist. Although Schrödinger has never had a school of his own, he has influenced physics immensely. There is scarcely a paper on atomic theory which does not refer to his name in connexion with his wave equation.

\section{Memorials to Dr. T. N. Annandale}

ON April 10 some past and present members of the Zoological Syrvey of India assembled at the Scottish Cemetery, Calcutta, to pay homage to the memory of Dr. Shomas Nelson Annandale, the founder. direct. 5 of the Survey, who died on April 10, 1924, twenty-five years ago. The Royal Asiatic Society of Bongal, with which he was closely associated through. out his period of service in India as anthropological secretary, vice-president, and as its president in 1923, perpetuates his memory by a triennial award of the Annandale Memorial Miedal to a person who has made the most important contribution, during the previous five years, to anthropology in Asia, and the first award was made to Dr. Fritz Sarasin in 1928. Thereafter the award has been made alternately for physical and cultural anthropology. The Society has a sepia portrait and an oil painting of Annandale. The Council of the Society is now appealing for funds to perpetuate the memory of Annandale. It is suggested that the balance of income of the Annandale Memorial Fund be suitably invested until the accumulated amount is sufficient, after paying for the triennial award, to provide Rs. 250 a year, to be utilized for a biennial anthropological lectureship. Annandale had been the last superintendent of the Indian Museum, and this office he held during 1907-16. $\mathrm{He}$ succeeded Colonel Alcock, and relinquished the office on becoming the first director of the Zoological Survey of India. The Trustees of the Indian Museum have also perpetuated his memory by putting up a brass tablet in the premises.

\section{Radioactive Substances Advisory Committee}

THE Minister of Health, the Secretary of State for Scotland, the Minister of Supply, and the Minister of Health and Local Government for Northern Ireland, have appointed a Radioactive Substances Advisory Commitce to advise on measures to safeguard workpeople and the public generally against the danger of exposure to radiation from radioactive substances and certain irradiating apparatus. The Committee consists of Sir Henry Dale (chairman); Dr. J. P. Baxter, Imperial Chemical Industries, Ltd., Research Department, Widnes Laboratory, Lancs; Mir. W. Binks, National Physical Laboratory; Sir Ernest Rock Carling ; Mr. D. G. Catcheside, Botany School, Cambridge; Lord Cherwell, Clarendon Laboratory, Oxford; Sir John Cockeroft, Atomic Energy Research Establishment, Harwell, Berks ; Prof. N. Feather, Department of Natural Philosophy, University of Edinburgh ; Dr. L. H. Gray, M.R.C. Radiotherapeutic Research Unit, Hammersmith Hospital, London, W.12 ; Capt. Mark Hewitson, M.P., National Union of General and Municipal Workers, 5 Endsleigh Gardens, London, W.C.1 ; Dr. J. F. Loutit, Radiobiological Research Unit, Atomic Energy Research Establishment, Harwell; Prof. W. V. Mayneord, Royal Cancer Hospital, London, S.W.3 ; Prof. R. McWhirter, Radiology Department, Royal Infirmary, Edinburgh 3 ; Dr. E. R. A. Mereweather, H.Mi. Senior Inspector of Factories, Ministry of Labour and National Service, London, S.W.1; Dr. Ralston 